Check for updates

Cite this: RSC Adv., 2017, 7, 46257

Received 14th September 2017 Accepted 22nd September 2017

DOI: 10.1039/c7ra10220h

rsc.li/rsc-advances

\title{
Regioselective alkylation of carbohydrates and diols: a cheaper iron catalyst, new applications and mechanism $\uparrow$
}

\author{
Bo Ren, (D) * Ningning Yan and Lu Gan
}

\begin{abstract}
As an extension of our previous research on the regioselective protection of carbohydrates and diols, we developed an iron catalyst, $\mathrm{Fe}(\mathrm{dibm})_{3}$ (dibm = diisobutyrylmethane), which has an unusually broad catalytic scope in the selective monoalkylation of diols and carbohydrates. However, even though the iron reagent is green, the cost to prepare the catalyst is high, which is not conducive to large-scale application, and the mechanism of the catalytic reaction is still not completely clear. In this study, we have developed a much cheaper iron catalyst, Fe(dipm) ${ }_{3}($ dipm $=$ dipivaloylmethane), which has a similar catalytic efficiency in the regioselective alkylation of carbohydrates and diols. The mechanism of the iron-catalyzed selective alkylation was also studied and a new detailed reaction mechanism for the iron catalysis was proposed.
\end{abstract}

\section{Introduction}

Regioselective protection is very important in organic chemistry especially in carbohydrate chemistry. ${ }^{1-5}$ Regioselective alkylation is always the most important reaction in the synthesis of oligosaccharide building blocks due to the stability of alkyl groups. ${ }^{6-11}$ Many metal compounds and organic small molecules have been employed in regioselective alkylation methods, including tin(Iv)-, ${ }^{12-16}$ boron(Iv)-, ${ }^{17,18}$ silver(I)-, ${ }^{19,20}$ and nickel(II)based complexes ${ }^{21}$ as well as the iron catalyst that we have reported. ${ }^{22,23}$ Organotin compounds were the most widely used reagents for selective alkylation reactions for many years, but their use must be limited due to their potential toxicity. ${ }^{24,25}$ Taylor's group developed the organoboron catalyzed regioselective alkylation of carbohydrates, which is a good way to avoid the use of a toxic catalyst. However, the scope this reaction limited its applicability. ${ }^{17,18}$ Methods that use metal salts can only achieve good selectivity for a small subset of substrates. ${ }^{19-21}$

In our previous study, we reported a $\mathrm{Fe}(\mathrm{dibm})_{3}$ (dibm, diisobutyrylmethane) catalyst that has an unusually broad substrate scope in the selective alkylation of carbohydrates, diols and polyols (Scheme 1a). ${ }^{22}$ This reaction could be used to completely replace the toxic organotin reagents in the regioselective protection of carbohydrates and polyols since iron is less expensive and non-toxic. ${ }^{26,27}$ Because this method is conducted at high temperature, we initially developed iron-catalyzed regioselective alkylation reactions with $\mathrm{Ag}_{2} \mathrm{O}$ and

College of Chemistry \& Chemical Engineering, Xinyang Normal University, Nanhu Road 237, Xinyang, Henan, 46400o, P. R. China. E-mail: renbo@xynu.edu.cn

$\dagger$ Electronic supplementary information (ESI) available. See DOI: $10.1039 / \mathrm{c} 7 \mathrm{ra} 10220 \mathrm{~h}$ tetrabutylammonium bromide (TBAB) as co-catalysts, which can efficiently proceed to completion in $2-3$ hours at $40{ }^{\circ} \mathrm{C}$ (Scheme 1b). ${ }^{23}$ Although iron is cheap and abundant, the organic ligand dibm is very expensive, which is an obstacle in the synthesis of this high-efficiency catalyst. We have been aware of this problem for a long time, and the key to solving this problem is to clarify the reaction mechanism to design a cheaper and more efficient iron catalyst.

After many control experiments, we successfully found a much cheaper iron catalyst, $\mathrm{Fe}(\mathrm{dipm})_{3}(\mathrm{dipm}=$ dipivaloylmethane), which costs $80 \%$ less than the $\mathrm{Fe}(\mathrm{dibm})_{3}$ catalyst (Scheme 1c) but has almost the same catalytic efficiency. To the best of our knowledge, this is one of the cheapest iron catalyst that can replace the excellent $\mathrm{Fe}(\mathrm{dibm})_{3}$ catalyst in the regioselective

a) Chem. Eur. J. 2016, 22, 2481

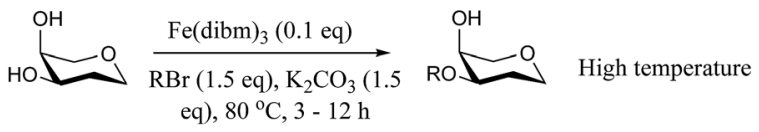

b) Chemcatchem 2017, 9, 950

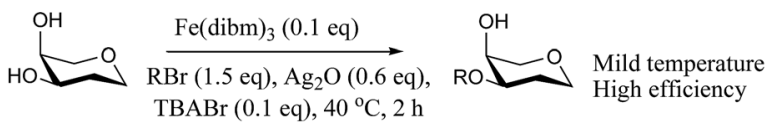

c) This work



Scheme 1 Comparison of this method with previous reported methods. 
alkylation of carbohydrates and polyols. It can also take the place of organotin catalysts and could be used on a large scale.

\section{Results and discussion}

Organotin reagents have been studied for a long time, and their mechanism in regioselective reactions has been hypothesized to be controlled by complex stannylene dimer or polymer structures. ${ }^{16,28}$ In 2012, Dong's group predicted that any reagent that could form cyclic dioxolane-type intermediates with hydroxyl groups could achieve similar selectivities to the organotin reagents. ${ }^{15}$ One of the best examples is the organoboron catalyst developed by Taylor's group. ${ }^{17,18}$ Another example may be the $\mathrm{Fe}(\mathrm{dibm})_{3}$ catalyst we developed, which shows excellent regioselectivities in selective alkylations. We have only proposed that the iron catalyst could form cyclic dioxolane/dioxane-type intermediates with the hydroxyl groups like the organotin reagents, but we have not explained how it forms the intermediates or why other iron reagents could not achieve similar regioselectivities.

First we chose methyl 4,6-O-benzylidene- $\alpha$-D-mannopyranoside, $\mathbf{1}$, as the substrate to carefully verify some of our hypotheses and found a better and cheaper iron catalyst (Table 1). Thus, 1 was treated with 1.1 equiv. of $\mathrm{BnBr}$ and 0.6 equiv. of $\mathrm{Ag}_{2} \mathrm{O}$ in the presence of a catalyst and 0.1 equiv. of TBAB as a cocatalyst in acetonitrile at $40{ }^{\circ} \mathrm{C}$ for $2-3 \mathrm{~h}$. The isolated yields were low when $\mathrm{FeCl}_{3}$ and $\mathrm{FeBr}_{3}$ were used as the catalysts (Table 1 , entries 2-3), which is consistent with previous reports. ${ }^{22}$ To

Table 1 Comparison of results obtained through variations of the standard conditions

$$
\text { . }
$$

\begin{tabular}{lll}
\hline Entry & Various conditions & Isolated yield (\%) \\
\hline 1 & Optimized condition & \\
2 & 0.1 eq. $\mathrm{FeCl}_{3}$ & 93 \\
3 & 0.1 eq. $\mathrm{FeBr}_{3}$ & $70^{b}$ \\
4 & 0.1 eq. $\mathrm{Zn}(\mathrm{acac})_{2}$ & $65^{b}$ \\
5 & 0.1 eq. $\mathrm{Cu}(\mathrm{acac})_{2}$ & 90 \\
6 & 0.1 eq. $\mathrm{Fe}(\mathrm{acac})_{3}$ & 91 \\
7 & 0.1 eq. $\mathrm{Fe}(\mathrm{dbzm})_{3}$ & 90 \\
8 & 0.1 eq. $\mathrm{Fe}(\mathrm{dibm})_{3}$ & 90 \\
9 & 0.1 eq. $\mathrm{Fe}(\mathrm{dipm})_{3}$ & 92 \\
10 & 0.05 eq. $\mathrm{Fe}(\mathrm{dipm})_{3}$ & 93 \\
11 & 0.1 eq. benzoylacetone & 88 \\
12 & 0.1 eq. acetylacetone & $40^{b}$ \\
13 & 0.1 eq. dibm & $42^{b}$ \\
14 & 0.1 eq. dipm & $50^{b}$ \\
15 & Without cat. & $50^{b}$ \\
16 & Without $\mathrm{Ag}{ }_{2} \mathrm{O}$ & $50^{b}$ \\
17 & Reaction at rt & $-{ }^{c}$ \\
& & $70^{b}$
\end{tabular}

${ }^{a}$ Reactant (50 mg), $\mathrm{BnBr}$ (1.1 eq.), cat. (0.05-0.1 eq.), $\mathrm{Ag}_{2} \mathrm{O}$ (0.6 eq.), TBAB (0.1 eq.), MeCN (1 mL), 2-3 h. ${ }^{b}$ Poor or no selectivity. ${ }^{c}$ Low conversion $(5-10 \%$ of 2$)$. our delight, when $\mathrm{Fe}(\mathrm{acac})_{3}$ was used as the catalyst, 3-O-benzylated mannoside, 2 , was isolated in $90 \%$ yield (Table 1, entry 6). This is in contrast with our previous reports making us wonder whether the ligands affected the catalysis efficiency. To test this hypothesis, $\mathrm{Zn}(\mathrm{acac})_{2}$ and $\mathrm{Cu}(\text { acac })_{2}$ were used as catalysts. To our surprise, product 2 was isolated in yields near $90 \%$ (Table 1, entries 4-5). Then we changed the ligands of iron catalysts. We then decided to test other ligands on iron. We made or bought three iron catalysts, $\mathrm{Fe}(\mathrm{dbzm})_{3}\left(\mathrm{Fe}(\mathrm{dbzm})_{3}=\right.$ tris(dibenzoylmethanato)iron), $\mathrm{Fe}(\mathrm{dibm})_{3}$, and $\mathrm{Fe}(\mathrm{dipm})_{3}$ (dipm = dipivaloylmethane), all of which were found to catalyze the reaction with good regioselectivity (Table 1, entries 7-10). To test whether the ligands can catalyze the reaction, four 1,3diketone ligands (benzoylacetone, acetylacetone, dibm and dipm) were also tested as catalysts. To our surprise, all the ligands reacted with the alkylation reagents, so the isolated yields were near $50 \%$, which is the same as it is without any catalyst (Table 1, entries 11-15).

On the chance that substrate 1 was not representative of all carbohydrates, we changed to methyl 6-O-(tert-butyldimethylsilyloxy)- $\alpha$-D-mannopyranoside, 3 , as the substrate to verify our hypothesis (Table 2). To our amazement, when 3 was subjected to the same reaction conditions, the three synthesized or purchased iron catalysts, $\mathrm{Fe}(\mathrm{dbzm})_{3}, \mathrm{Fe}(\mathrm{dibm})_{3}$, and $\mathrm{Fe}(\mathrm{dipm})_{3}$, all afforded isolated yields of the desired product near $90 \%$ (Table 2, entries 7-10). However, when Fe(dbzm) $)_{3}$ was used as the catalyst, some benzoylated carbohydrate by-product was observed. All other catalysts afforded poor regioselectivities.

Table 2 Control experiments based on variations of the standard conditions

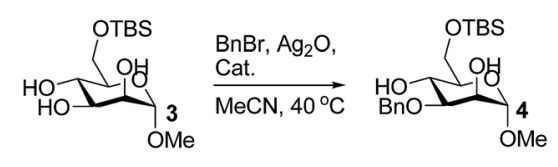

\begin{tabular}{lll}
\hline Entry & Various conditions & Isolated yield (\%) \\
\hline 1 & Optimized condition $^{a}$ & 91 \\
2 & 0.1 eq. $\mathrm{FeCl}_{3}$ & $60^{b}$ \\
3 & 0.1 eq. $\mathrm{FeBr}_{3}$ & $55^{b}$ \\
4 & 0.1 eq. $\mathrm{Zn}(\mathrm{acac})_{2}$ & $53^{b}$ \\
5 & 0.1 eq. $\mathrm{Cu}(\mathrm{acac})_{2}$ & $54^{b}$ \\
6 & 0.1 eq. $\mathrm{Fe}(\mathrm{acac})_{3}$ & $52^{b}$ \\
7 & 0.1 eq. $\mathrm{Fe}(\mathrm{dbzm})_{3}$ & 85 \\
8 & 0.1 eq. $\mathrm{Fe}($ dibm) & 91 \\
9 & 0.1 eq. $\mathrm{Fe}(\text { dipm })_{3}$ & 91 \\
10 & 0.05 eq. $\mathrm{Fe}(\text { dipm })_{3}$ & 88 \\
11 & 0.1 eq. benzoylacetone & $40^{b}$ \\
12 & 0.1 eq. acetylacetone & $42^{b}$ \\
13 & 0.1 eq. dibm & $51^{b}$ \\
14 & 0.1 eq. dipm & $53^{b}$ \\
15 & Without cat. & $50^{b}$ \\
16 & Without Ag ${ }_{2} \mathrm{O}$ & $-{ }^{c}$ \\
17 & Reaction at rt & $61^{b}$ \\
& &
\end{tabular}

${ }^{a}$ Reactant (50 mg), $\mathrm{BnBr}$ (1.1 eq.), cat. (0.05-1.0 eq.), $\mathrm{Ag}_{2} \mathrm{O}$ (0.6 eq.), $\operatorname{TBAB}\left(0.1\right.$ eq.), MeCN (1 mL), $2-3$ h. ${ }^{b}$ Poor or no selectivity. ${ }^{c}$ Low conversion $(5-10 \%$ of 4$)$. 
Table 3 Fe(dipm) ${ }_{3}$-catalyzed selective alkylation of cis-carbohydrates with $\mathrm{Ag}_{2} \mathrm{O}$ and bromide anion as co-catalysts ${ }^{a}$

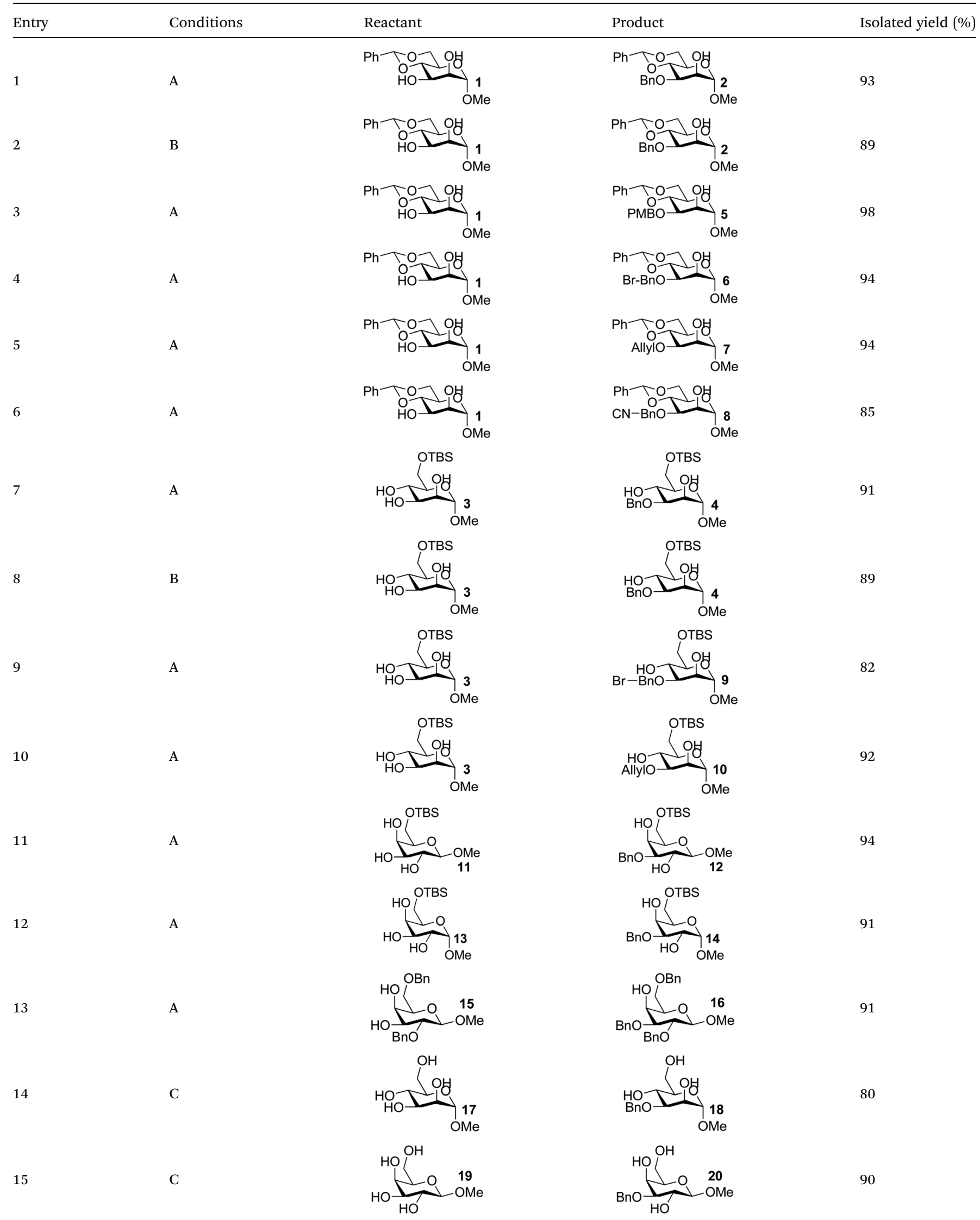


Table 3 (Contd.)

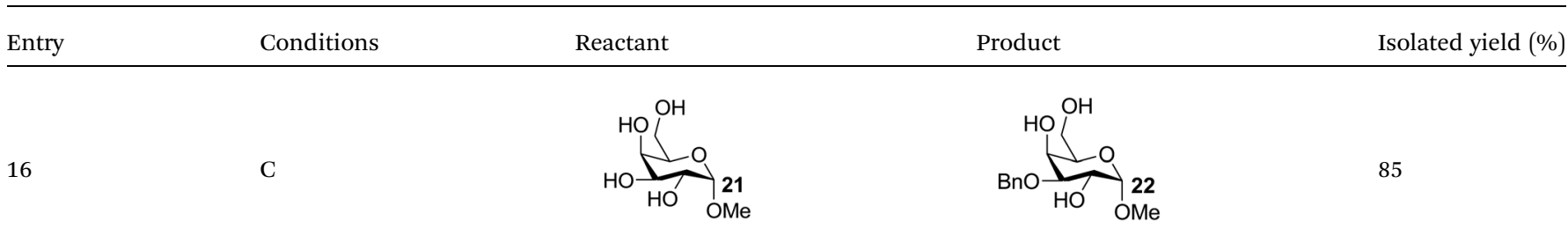

\footnotetext{
${ }^{a}$ Reaction conditions: (A) $50 \mathrm{mg}$ substrate, $1 \mathrm{~mL} \mathrm{MeCN}, 0.1$ eq. $\mathrm{Fe}(\mathrm{dipm})_{3}, 0.6$ eq. $\mathrm{Ag}_{2} \mathrm{O}, 0.1$ eq. TBAB, 1.1 eq. $\mathrm{BnBr} / \mathrm{PMBCl} / 4-\mathrm{Br}-\mathrm{BnBr} / \mathrm{allyl} \mathrm{bromide}$, $40{ }^{\circ} \mathrm{C}, 2 \mathrm{~h}$. (B) $50 \mathrm{mg}$ substrate, $1 \mathrm{~mL} \mathrm{MeCN}, 0.1$ eq. Fe(dipm) $)_{3}, 1.5$ eq. $\mathrm{K}_{2} \mathrm{CO}_{3}, 1.1$ eq. $\mathrm{BnBr}, 80^{\circ} \mathrm{C}, 12 \mathrm{~h} .(\mathrm{C}) 50 \mathrm{mg}$ substrate, $1 \mathrm{~mL} \mathrm{MeCN}+0.1 \mathrm{~mL}$ DMF, 0.1 eq. $\mathrm{Fe}(\mathrm{dipm})_{3}, 0.6$ eq. $\mathrm{Ag}_{2} \mathrm{O}, 0.1$ eq. $\mathrm{TBAB}, 1.1$ eq. $\mathrm{BnBr}, 40^{\circ} \mathrm{C}, 3 \mathrm{~h}$.
}

Therefore, only the $\mathrm{Fe}(\mathrm{dipm})_{3}$ catalyst has the same catalytic efficiency as what has been reported for $\mathrm{Fe}(\mathrm{dibm})_{3}$. In addition, a big advantage is that the dipm ligand cost $20 \%$ as much as the dibm ligand, which makes the catalyst easier to acquire.

To test the catalytic efficiency and substrate scope of the $\mathrm{Fe}(\mathrm{dibm})_{3}$ catalyst, this new method was further tested with cis-carbohydrates and with other alkylating agents (Table 3). For all the tested substrates, the equatorial hydroxyl group was selectively alkylated in isolated yields of $80-98 \%$ in $2-3$ hours. Substrates 1 and 3 were alkylated with different alkylating reagents in good isolated yields (Table 3, entries 1-10). To verify the catalytic efficiency of $\mathrm{Fe}(\mathrm{dibm})_{3}$, we treated substrates 1 and 3 with $\mathrm{K}_{2} \mathrm{CO}_{3}$ as the base in $80^{\circ} \mathrm{C}$, as we have previously reported; ${ }^{22}$ both desired products were isolated yields of $89 \%$ (Table 3, entries 2 and 8 ). The unprotected glycosides were alkylated in a mixed solvent system (MeCNDMF, $10: 1$ ) due to their poor solubility in MeCN alone (Table 3 , entries 14-16). All the tests showed that the Fe(dipm) ${ }_{3}$ catalyst had almost the same catalytic efficiency as has been reported for $\mathrm{Fe}(\mathrm{dibm})_{3}$.

Table 4 Fe(dipm) $)_{3}$-catalyzed selective benzylation of other carbohydrates and diols with $\mathrm{Ag}_{2} \mathrm{O}$ and bromide anion as co-catalysts ${ }^{a}$

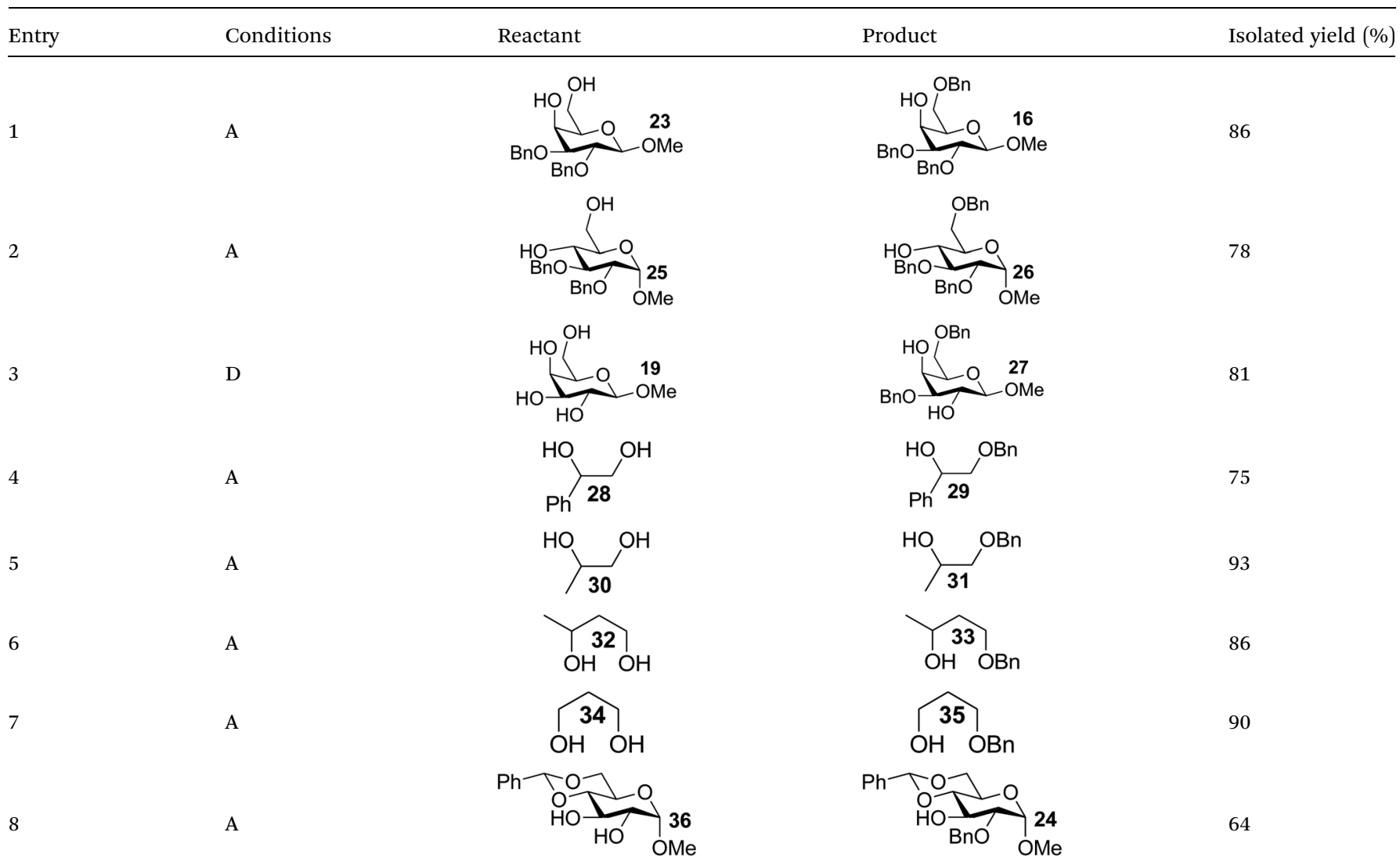

${ }^{a}$ Reaction conditions: (A) $50 \mathrm{mg}$ substrate, $1 \mathrm{~mL} \mathrm{MeCN}, 0.1$ eq. $\mathrm{Fe}(\mathrm{dipm})_{3}, 0.6$ eq. $\mathrm{Ag}_{2} \mathrm{O}, 0.1$ eq. TBAB, 1.1 eq. $\mathrm{BnBr} / \mathrm{PMBCl} / 4-\mathrm{Br}-\mathrm{BnBr} / \mathrm{allyl} \mathrm{bromide}$, $40{ }^{\circ} \mathrm{C}, 3 \mathrm{~h}$. (D) (1) $50 \mathrm{mg}$ substrate, $1 \mathrm{~mL} \mathrm{MeCN}, 0.1$ eq. Fe(dipm) $)_{3}, 0.6$ eq. $\mathrm{Ag}_{2} \mathrm{O}, 0.1$ eq. TBAB, 1.1 eq. $\mathrm{BnBr}, 40{ }^{\circ} \mathrm{C}, 3 \mathrm{~h}$. (2) Add 1.5 eq. $\mathrm{NaOH}$ and 1.5 eq. $\mathrm{BnBr}, 40^{\circ} \mathrm{C}, 3 \mathrm{~h}$. 
The Fe(dipm $)_{3}$ catalyst was further used in the alkylation of 1,2- or 1,3-diols and carbohydrates with other configurations (Table 4). For the glycosides containing 1,3-diols (23 and 25) and non-carbohydrate 1,2- and 1,3-diols $(\mathbf{2 8}, \mathbf{3 0}, \mathbf{3 2}$, and 34$)$, the terminal hydroxyl group was alkylated in 75-93\% isolated yields (Table 4, entries 1, 2 and 4-7). Thus, we can selectively alkylate the primary hydroxyl groups in 1,2- or 1,3-diols with the optimized conditions. As reported, trans-carbohydrates were not isolated in good yields with $\mathrm{Ag}_{2} \mathrm{O}$ (Table 4, entry 8). ${ }^{17}$ Then, we tested replacing the organotin reagent with $\mathrm{Fe}(\operatorname{dipm})_{3}$ in the production of dibenzylated carbohydrate 27 , which was obtained in $81 \%$ isolated yield (Table 4 , entry 3 ). ${ }^{14}$ All tests showed that this method could achieve isolated yields that were just as high as those obtained with $\mathrm{Fe}(\mathrm{dibm})_{3}$ and may be able to replace the toxic organotin reagents in the future.

In our previous report, we only proposed that a cyclic dioxolane-type intermediate with two hydroxyl groups plays a key role in the catalytic cycle. However, this was over simplified, and there was little evidence to support such a mechanism. Additionally, we did not address the formation of the intermediates and why similar regioselectivities could not be achieved with other iron reagents.

To elucidate the mechanism and its key controlling factors, we conducted many control experiments. Initially, we speculated that the 1,3-diketone ligands may be the key factor controlling the efficiency of this catalyst. However, the control experiments showed that the ligands did not catalyzed the reaction; they the simply reacted with the $\mathrm{BnBr}$ under basic conditions (Fig. S2 $\dagger$ ), and we realized that this was the reason other iron catalysts were not delivering the same regioselectivities. We always thought the $\mathrm{Fe}(\text { dibm })_{3}$ catalyst could be recycled like organoboron catalysts, meaning the $\mathrm{Fe}(\mathrm{dibm})_{3}$ catalyst was not changed during the reaction. However, our recycling experiments were puzzling; the catalyst could only be recycled 2-3 times, and the isolated yield dropped with every cycle. The only reasonable explanation is that the catalyst had changed or degraded in some way. Therefore, we believe that $\mathrm{BnBr}$ reacted with the ligand on the $\mathrm{Fe}(\mathrm{dibm})_{3}$ or $\mathrm{Fe}(\text { dibm })_{3}$ catalysts, which caused the iron catalyst to form a cyclic dioxolane intermediate with adjacent hydroxyl groups. Each time the iron catalyst went through the catalytic cycle, it was sequentially converted from $\mathrm{Fe}(\mathrm{L})_{3}$ to $\mathrm{Fe}(\mathrm{L})_{2} \mathrm{OH}, \mathrm{FeL}(\mathrm{OH})_{2}$ and $\mathrm{Fe}(\mathrm{OH})_{3}$, which caused its catalytic efficiency to decrease after 2-3 cycles because it could no longer form the cyclic dioxolane intermediates with the substrates. This also explains why we could not isolate the stable cyclic dioxolane intermediates, as was possible with the organotin reagents. $\mathrm{BnBr}$ immediately reacted with the intermediate after activation of the iron catalyst. This theory also explains why other iron catalysts did not perform as well in the catalytic regioselective alkylation of carbohydrates. Some ligands, such as benzoylacetone and acetylacetone, are not stable under these reaction conditions; they are easily decomposed by the higher temperatures, or the ligand is consumed by reaction with the alkylation reagents. In contrast, some ligands are too stable to activate the catalyst. Only the appropriate ligands, such as dibm and dipm, can properly activate the reaction; they are neither too stable nor too reactive, which ensures the iron catalyst is activated and can be recycled.

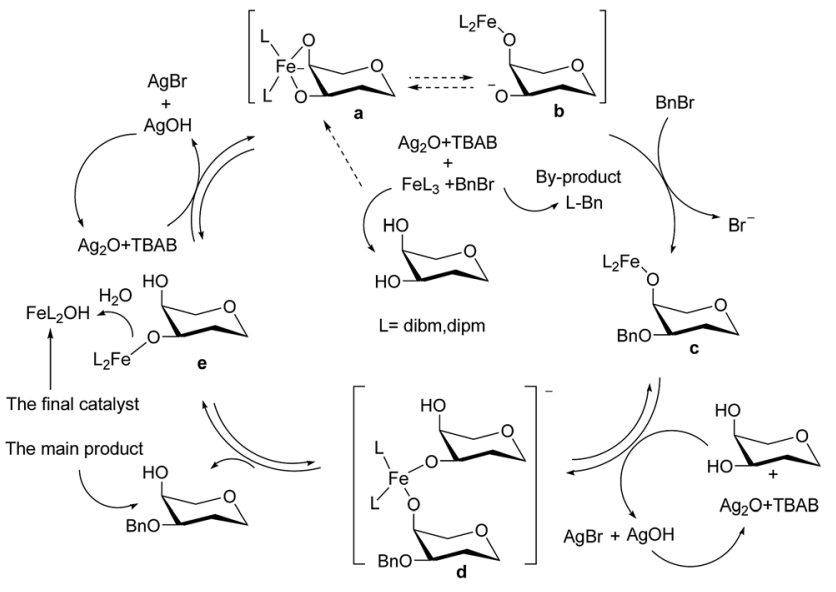

Scheme 2 Proposed detailed catalytic cycle.

Therefore, we proposed the detailed mechanism for the $\mathrm{Fe}(\mathrm{dibm})_{3}$ - or $\mathrm{Fe}(\mathrm{dibm})_{3}$-catalyzed reactions shown in (Scheme 2). First, $\mathrm{BnBr}$ reacted with the ligand on the iron catalyst, and at the same time, the cyclic dioxolane intermediate a formed between the substrate and $\mathrm{Fe}^{+}(\mathrm{L})_{2}$. Intermediate a then reacted with $\mathrm{BnBr}$ to form c, and then, $\mathbf{c}$ transferred the iron catalyst to another substrate as it proceeded to form $\mathbf{d}$ via the deprotonation of the hydroxyl group by $\mathrm{Ag}_{2} \mathrm{O}$ and TBAB. The main alkylated product was released during the conversion of $\mathbf{d}$ to $\mathbf{e}$, and finally, e was converted to a by deprotonation with $\mathrm{Ag}_{2} \mathrm{O}$ and TBAB. After the completion of the reaction, the iron catalyst was turned into $\mathrm{Fe}(\mathrm{L})_{2} \mathrm{OH}$ by residual water in silica gel during flash column chromatography.

\section{Conclusions}

We successfully found a much cheaper iron catalyst, Fe(dipm) $)_{3}$ (dipm $=$ dipivaloylmethane), which costs only $20 \%$ as much as $\mathrm{Fe}(\mathrm{dibm})_{3}$ but has almost the same catalytic efficiency. To the best of our knowledge, this is one of the cheapest iron catalyst that can replace the excellent $\mathrm{Fe}(\mathrm{dibm})_{3}$ catalyst in regioselective alkylations of carbohydrates and polyols. It can also take the place of organotin catalysts, and it could be used on a large scale. After carefully studying these reactions, we elucidated the mechanism, which can explain all the unusual results in the study.

\section{Experimental section}

\section{General}

All commercially available starting materials and solvents were of reagent grade and used without further purification. Chemical reactions were monitored with thin-layer chromatography using precoated silica gel $60(0.25 \mathrm{~mm}$ thickness $)$ plates. ${ }^{1} \mathrm{H}$ NMR and ${ }^{13} \mathrm{C}$ NMR spectra were recorded using a Bruker Avance 400 instrument or a Bruker DMX 500 instrument at $298 \mathrm{~K}$ in $\mathrm{CDCl}_{3}$, using the residual signals from $\mathrm{CHCl}_{3}\left({ }^{1} \mathrm{H}: \delta=7.25 \mathrm{ppm}\right.$; ${ }^{13} \mathrm{C}: \delta=77.2 \mathrm{ppm}$ ) as the internal standard. ${ }^{1} \mathrm{H}$ NMR peak assignments were made by first-order analysis of the spectra, supported by standard ${ }^{1} \mathrm{H}-{ }^{1} \mathrm{H}$ NMR correlation spectroscopy (COSY). 


\section{General method for regioselective alkylation of diols and} polyols

(1) The substrates $(50 \mathrm{mg})$ were allowed to react with $\mathrm{RX}$ (alkylation reagents) (1.1 eq.) in dry acetonitrile $(1 \mathrm{~mL})$ or a mixed solvent (MeCN/DMF: $10 / 1$ ) at $40{ }^{\circ} \mathrm{C}$ for $2-3 \mathrm{~h}$ in the presence of $\mathrm{Ag}_{2} \mathrm{O}$ (0.6 eq.), TBAB (0.1 eq.) and $\mathrm{Fe}(\mathrm{dipm})_{3}(0.1$ eq.). The reaction mixtures were filtered and directly purified by flash column chromatography (hexanes/EtOAc $=3: 1$ to $1: 1$ ) to afford the pure products.

(2) Diol and polyol reactants $(50 \mathrm{mg})$ were allowed to react with $\mathrm{RX}$ (alkylation reagents) (1.1 eq.) in $1 \mathrm{~mL}$ of dry acetonitrile at $80{ }^{\circ} \mathrm{C}$ for $8 \mathrm{~h}$, in the presence of $\mathrm{Fe}(\mathrm{dipm})_{3}\left(0.1\right.$ eq.) and $\mathrm{K}_{2} \mathrm{CO}_{3}$ (1.5 eq.). After cooling and evaporating the solvent, the reaction mixture was directly purified by flash column chromatography (hexanes-EtOAc $3: 1$ to $1: 1$ ), affording the pure products.

The procedure for producing the $\mathrm{Fe}(\mathrm{dibm})_{3}$ catalyst was reported in ref. 29. In addition, the $\mathrm{Fe}(\mathrm{dipm})_{3}$ catalyst was prepared by the same procedure as was used for $\mathrm{Fe}(\mathrm{dibm})_{3}$.

Spectroscopic data of the known products were in accordance with those reported in the literature.

\section{Conflicts of interest}

There are no conflicts to declare.

\section{Acknowledgements}

This study was supported by the Henan Key Scientific Research Project (18A150015) and the Nanhu Scholars Program for Young Scholars of XYNU. This study was also supported by the Doctoral Research Foundation of Xinyang Normal University (Grant Number: 16070). The authors also thank Dr Shitao Fu of HUST for support with the NMR instruments.

\section{References}

1 C. Wang, J. Lee, S. Luo, S. S. Kulkarni, Y. Huang, C. Lee, K. Chang and S. Hung, Nature, 2007, 446, 896-899.

2 G. Xiao, G. A. Cintron-Rosado, D. A. Glazier, B. Xi, C. Liu, P. Liu and W. Tang, J. Am. Chem. Soc., 2017, 139, 4346-4349.

3 P. Peng, M. Linseis, R. F. Winter and R. R. Schmidt, J. Am. Chem. Soc., 2016, 138, 6002-6009.

4 B. Ren, M. Rahm, X. L. Zhang, Y. X. Zhou and H. Dong, J. Org. Chem., 2014, 79, 8134-8142.

5 K. L. M. Hoang and X. Liu, Nat. Commun., 2014, 5, 50515060 .
6 Y. Park, K. C. Harper, N. Kuhl, E. E. Kwan, R. Y. Liu and E. N. Jacobsen, Science, 2017, 355, 162-166.

7 Y. Wu, D. Xiong, S. Chen, Y. Wang and X. Ye, Nat. Commun., 2017, 8, 14851.

8 Q. Zhang, E. R. van Rijssel, M. T. C. Walvoort, H. S. Overkleeft, G. A. van der Marel and J. D. C. Codée, Angew. Chem., Int. Ed., 2015, 54, 7670-7673.

9 D. Schmidt, F. Schuhmacher, A. Geissner, P. H. Seeberger and F. Pfrengle, Chem.-Eur. J., 2015, 21, 5709-5713.

10 D. Zhu, K. N. Baryal, S. Adhikari and J. Zhu, J. Am. Chem. Soc., 2014, 136, 3172-3175.

11 P. Peng and R. R. Schmidt, Acc. Chem. Res., 2017, 50, 11711183.

12 M. Giordano and A. Iadonisi, J. Org. Chem., 2014, 79, 213222.

13 H. Xu, Y. Lu, Y. Zhou, B. Ren, Y. Pei, H. Dong and Z. Pei, Adv. Synth. Catal., 2014, 356, 1735-1740.

14 Y. Zhou, J. Li, Y. Zhan, Z. Pei and H. Dong, Tetrahedron, 2013, 69, 2693-2700.

15 H. Dong, Y. Zhou, X. Pan, F. Cui, W. Liu, J. Liu and O. Ramström, J. Org. Chem., 2012, 77, 1457-1467.

16 T. B. Grindley, Adv. Carbohydr. Chem. Biochem., 1998, 53, 17142.

17 D. Lee, C. L. Williamson, L. Chan and M. S. Taylor, J. Am. Chem. Soc., 2012, 134, 8260-8267.

18 L. Chan and M. S. Taylor, Org. Lett., 2011, 13, 3090-3093.

19 B. Ren, M. Wang, J. Liu, J. Ge and H. Dong, ChemCatChem, 2015, 7, 761-765.

20 S. Malik, V. A. Dixit, P. V. Bharatam and K. P. R. Kartha, Carbohydr. Res., 2010, 345, 559-564.

21 U. B. Gangadharmath and A. V. Demchenko, Synlett, 2004, 2191-2193.

22 B. Ren, O. Ramstrom, Q. Zhang, J. Ge and H. Dong, Chem.Eur. J., 2016, 22, 2481-2486.

23 B. Ren, J. Lv, Y. Zhang, J. Tian and H. Dong, ChemCatChem, 2017, 9, 950-953.

24 S. M. Jenkins, K. Ehman and S. Barone, Dev. Brain Res., 2004, 151, 1-12.

25 M. M. Whalen, B. G. Loganathan and K. Kannan, Environ. Res., 1999, 81, 108-116.

26 I. Bauer and H. J. Knolker, Chem. Rev., 2015, 115, 3170-3387.

27 B. D. Sherry and A. Fuerstner, Acc. Chem. Res., 2008, 41, 1500-1511.

28 S. David and A. Thiéffry, Tetrahedron Lett., 1981, 22, 26472650.

29 J. C. Lo, J. Gui, Y. Yabe, C. Pan and P. S. Baran, Nature, 2014, 516, 343-348. 